\title{
Implementation of a Robust Fuzzy Adaptive Speed Tracking Control System for Permanent Magnet Synchronous Motors
}

\author{
Jin-Woo Jung ${ }^{*}$, Han Ho Choi ${ }^{*}$, and Dong-Myung Lee ${ }^{\dagger}$ \\ *Division of Electronics and Electrical Engineering, Dongguk University, Seoul, Korea \\ ${ }^{\dagger}$ School of Electronic and Electrical Engineering, Hongik University, Seoul, Korea
}

\begin{abstract}
This paper presents a fuzzy adaptive speed controller that guarantees a fast dynamic behavior and a precise trajectory tracking capability for surfaced-mounted permanent magnet synchronous motors (SPMSMs). The proposed fuzzy adaptive control strategy is simple and easy to implement. In addition, the proposed speed controller is very robust to system parameter and load torque variations because it does not require any accurate parameter values. The global stability of the proposed control system is analytically verified. To evaluate the proposed fuzzy adaptive speed controller, both simulation and experimental results are shown under motor parameter and load torque variations on a prototype SPMSM drive system.
\end{abstract}

Key words: Adaptive control, Fuzzy control, Permanent magnet synchronous motor (PMSM), Speed control, Uncertainties

\section{NOMENCLATURE}

$\theta:$ Electrical rotor position;

$\theta_{d}:$ Desired electrical rotor position;

$\omega$ : Electrical rotor angular speed;

$\omega_{d}$ : Desired electrical rotor angular speed;

$e_{1}: \theta-\theta_{d}=\int_{0}^{t}\left(\omega-\omega_{d}\right) d \tau$

$e_{2}: \omega-\omega_{d}$

$i_{q s}: q$-axis current;

$i_{q s d}:$ Desired $q$-axis current;

$i_{d s}: d$-axis current;

$i_{d s d}:$ Desired $d$-axis current;

$V_{q s}: q$-axis control input voltage;

$V_{d s}: d$-axis control input voltage;

$T_{L}:$ Load torque;

$p:$ Number of poles;

$R_{s}:$ Stator resistance;

$L_{s}:$ Stator inductance;

$J$ : Rotor equivalent inertia;

Manuscript received Apr. 16, 2012; revised Jun. 15, 2012

Recommended for publication by Associate Editor Dwivedi K. Sanjeet.

${ }^{\dagger}$ Corresponding Author: dmlee@hongik.ac.kr

Tel: +82-2-320-3047, Hongik University

*Division of Electronics and Electrical Engineering, Dongguk University, Korea
$B$ : Viscous friction coefficient;

$\lambda_{m}$ : Magnetic flux;

\section{INTRODUCTION}

Permanent magnet synchronous motor (PMSM) drives have been used for various industrial applications such as electric vehicles (EV, Plug-in Hybrid EV, Fuel Cell EV), CNC machine tools, hard disk drives, and industrial robots since they have some excellent characteristics [1]-[17], such as high efficiency, low noise, low inertia, robustness, high torque to current ratio, etc. Unfortunately, PMSMs are not easy to control because they have nonlinearities due to nonlinear magnetic materials and coupling of the state variables (currents and speed) in the dynamic model. To guarantee a fast transient response and an excellent trajectory tracking capability, various nonlinear control methods such as [4]-[13] have been reported. These methods include robust control [4], disturbance observer based control [5]-[7], adaptive control [8]-[9], nonlinear feedback linearization [10]-[11], and neural network control [12], [13]. However, most of the previous control algorithms have been established on the assumption that knowledge of the PMSM parameters is available. In recent years, some PMSM control schemes based on the fuzzy control theory [14]-[17] have also been presented. These fuzzy PMSM control methods 
[14]-[17] may give a satisfactory performance. However, there have been no systematic and consistent design techniques to prove the stability of closed-loop fuzzy control systems because they are based on the heuristics-based fuzzy approach [18]. In addition, the control performance of the PMSM can be seriously affected by system parameter variations and external disturbances. Consequently, most previous control strategies may not satisfy the requirements for closed-loop system stability under uncertainties such as motor parameter and load torque variations.

Meanwhile, the fuzzy adaptive control design has been an alternative solution which can control uncertain nonlinear systems [18], [19]. The fundamental design procedure of the fuzzy adaptive control system is as follows: first, a fuzzy model is constructed to identify the input/output behaviors of an uncertain system; next, a controller for the uncertain system is designed; and then adaption control laws are decided to tune the parameters of the fuzzy model.

This paper proposes a fuzzy adaptive speed controller which can ensure a fast transient response and an accurate tracking capability for surfaced-mounted permanent magnet synchronous motors (SPMSMs). The proposed fuzzy adaptive control algorithm is simple and easy to implement. Furthermore, the proposed control method is very robust to variations of the motor parameters and load torque since it does not require exact system parameter and load torque values. The proposed speed control law consists of two terms: a feedback term and a fuzzy adaptive compensating term. That is, the feedback term stabilizes the error dynamics, while the fuzzy adaptive compensating term makes up for model parameter and load torque variations. In this paper, the global stability of the proposed fuzzy adaptive control system is analytically proven. To validate the feasibility of the proposed fuzzy adaptive speed controller, simulation and experimental results are presented under uncertainties (i.e., motor parameter and load torque variations) with a prototype SPMSM drive system.

This paper is organized as follows. Section II describes the design problem. The design and stability analysis of the proposed fuzzy adaptive controller are fully illustrated in Section III. Section VI gives simulation and experimental results to prove the effectiveness of the proposed control algorithm. Finally, conclusions are presented in Section V.

\section{DESIGN PROBLEM DESCRIPTION}

The dynamic model of a surface-mounted PMSM (SPMSM) where the $d$-axis of the synchronously rotating reference frame is oriented to the rotor flux vector is given by:

$$
\begin{aligned}
& \dot{\omega}=k_{1} i_{q s}-k_{2} \omega-k_{3} T_{L} \\
& \dot{i}_{q s}=-k_{4} i_{q s}-k_{5} \omega+k_{6} V_{q s}-\omega i_{d s} \\
& \dot{i}_{d s}=-k_{4} i_{d s}+k_{6} V_{d s}+\omega i_{q s}
\end{aligned}
$$

where:

$$
\begin{aligned}
& k_{1}=\frac{3}{2} \frac{1}{J} \frac{p^{2}}{4} \lambda_{m}, k_{2}=\frac{B}{J}, k_{3}=\frac{p}{2 J}, \\
& k_{4}=\frac{R_{s}}{L_{s}}, k_{5}=\frac{\lambda_{m}}{L_{s}}, k_{6}=\frac{1}{L_{s}}
\end{aligned}
$$

Note that the load torque disturbance $T_{L}$ as well as the uncertainties of the parameters $k_{i}$ can directly affect the control performance.

To design a robust fuzzy adaptive speed controller, the following assumptions are made:

A1: $\omega, i_{q s}$, and $i_{d s}$ are measurable.

A2: The desired speed $\omega_{d}$ is constant.

Most of the previous PMSM control schemes use the assumptions A1-2, and almost all of the previous methods are based on the restrictive assumption that $k_{i}$ is accurately known. Fig. 1 shows a block diagram of a general vector-controlled SPMSM control system. As shown in Fig. 1, the position or speed controller outputs the desired $q$-axis current $i_{q s d}$ which is used as the input of the current controller. Then from the desired and measured $q d$ currents, the current controller properly generates control inputs $\left(V_{q s}, V_{d s}\right)$ that can regulate the motor speed $(\omega)$ and the electromagnetic torque. Note that the desired $d$-axis current $i_{d s d}$ is usually set to zero. There is an exception for a field-weakening operation over rated speed. For field-oriented control (FOC), the two actual phase currents $\left(i_{a}, i_{b}\right)$ are measured and then transformed into $q$-axis and $d$-axis currents $\left(i_{q s}, i_{d s}\right)$ using coordinate transformation formulas (i.e., Park's and Clarke's transformations).

Using the FOC system, the PMSM drive system can be reduced to the following first-order dynamic equation [6], [9]:

$$
\dot{\omega}(t)=k_{1} i_{q s}(t)-k_{2} \omega(t)-k_{3} T_{L}
$$

It should be noted that many previous FOC methods such as [6], [9] were developed by using the above first-order equation (2). Considering this fact, the focus of this paper will be on proposing a fuzzy adaptive speed controller that produces a $q$-axis command current $i_{q s d}$ for the speed dynamic model (2) under the assumptions A1-2. Furthermore, a conventional PI current controller will be adopted to evaluate the overall performance of the proposed speed controller.

The following lemmas will be used to prove the stability of the proposed control system.

Lemma 1 [20]: Consider the following linear system:

$$
\dot{x}(t)=A x(t)+B u(t), \quad y(t)=C x(t)
$$

where $x \in R^{n} ; u \in R^{m} ; y \in R^{p}$; and $A, B$, and $C$ are constant matrices with appropriate dimensions. Assume that the control input $u(t)$ belongs to $L_{2}$ and the transfer function 


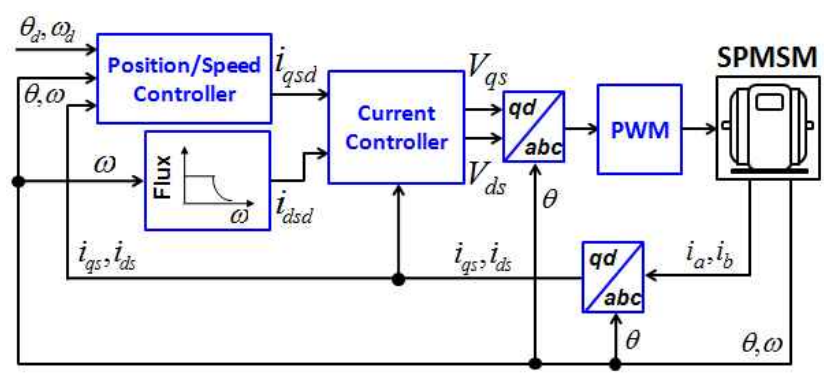

Fig. 1. Block diagram of a general vector-controlled SPMSM control system.

$C(s I-A)^{-1} B$ is stable and strictly proper. Then $y(t)$ is continuous and it converges to zero.

Lemma 2 [20]: Let $f(t)$ be a differentiable function of $t$. If $f(t)$ is bounded and $f(t)$ has a finite limit as time approaches infinity, then $f(t)$ converges to zero.

\section{FUZZY ADAPTIVE CONTROLLER DESIGN AND STABILITY ANALYSIS}

By introducing the error vector $e=\left[\begin{array}{ll}e_{1} & e_{2}\end{array}\right]^{T}$ where $e_{1}=\int_{0}^{t} e_{2} d \tau$ and $e_{2}=\omega-\omega_{d}$, the following error dynamics can be obtained from (2):

$$
\begin{aligned}
& \dot{e}_{1}=e_{2} \\
& \dot{e}_{2}=k_{1} i_{q s}-k_{2} \omega-k_{3} T_{L}
\end{aligned}
$$

The error dynamics (3) is rearranged as:

$$
\begin{aligned}
& \dot{e}_{1}=e_{2} \\
& \dot{e}_{2}=-\gamma e_{2}+k_{1}\left[i_{q s}-\eta(t)\right]
\end{aligned}
$$

where $\eta(t)$ is defined as:

$$
\eta(t)=\frac{1}{k_{1}}\left(k_{2} \omega+k_{3} T_{L}-\gamma e_{2}\right)
$$

and $\gamma>0$ is a design parameter.

Theorem 1: Assume that the term $\eta(t)$ of (5) is accurately known. Let $i_{q s}=i_{q s d}$ be given by:

$$
i_{q s}=i_{q s d}=-\delta \sigma+\eta(t)
$$

where $\delta>0, \sigma=\gamma e_{1}+e_{2}$, and $\gamma>0$. Then, $e$ converges to zero.

Proof: Define the Lyapunov functional as:

$$
V_{0}=\frac{1}{2}\left[\kappa e_{1}^{2}+\sigma^{2}\right]
$$

where $\kappa$ is a sufficiently small positive constant satisfying:

$$
4 \delta \gamma k_{1}>\kappa>0
$$

The time derivative of (7) along the error dynamics (4) is written by:

$$
\dot{V}_{0}=\kappa e_{1} \dot{e}_{1}+\sigma \dot{\sigma}
$$

The error dynamics (4) implies that:

$$
\begin{aligned}
& \dot{\sigma}=\gamma \dot{e}_{1}+\dot{e}_{2}=\gamma e_{2}-\gamma e_{2}+k_{1}\left[i_{q s}-\eta(t)\right] \\
& =\gamma e_{2}-\gamma e_{2}+k_{1}[-\delta \sigma+\eta(t)-\eta(t)]=-k_{1} \delta \sigma
\end{aligned}
$$

Thus, (9) can be reduced to:

$$
\dot{V}_{0} \leq \kappa e_{1}\left(\sigma-\gamma e_{1}\right)-k_{1} \delta \sigma^{2}=-e_{r}^{T} Q e_{r}
$$

where $e_{r}=\left[e_{1}, \sigma\right]^{T}$ and $Q$ is a $2 \times 2$ matrix given by:

$$
Q=\left[\begin{array}{cc}
\kappa \gamma & -0.5 \kappa \\
-0.5 \kappa & k_{1} \delta
\end{array}\right]
$$

which is positive definite as long as the inequality (8) is satisfied. This completes the proof.

$\nabla \nabla \nabla$

The term $i_{q s d}$ of (6) requires accurate knowledge of $\eta(t)$. Because $\eta(t)$ is not known accurately, a $r$-rule fuzzy model $\eta_{f}(t)$ is applied to approximate $\eta(t)$. The $i$ th fuzzy rule of $\eta_{f}(t)$ is of the following form:

Rule i for $\eta_{f}(t)$ : IF $e_{1}$ is $F_{l i}$ and $e_{2}$ is $F_{2 i}$, THEN $\eta_{f}(t)$ is $G_{i}$.

where $F_{1 i}$ and $F_{2 i}(i=1, \cdots, r)$ denote the fuzzy sets associated with $e_{1}$ and $e_{2}$, where $r$ is the number of fuzzy rules and $G_{i}$ are the fuzzy singletons for $\eta_{f}(t)$. The fuzzy sets $F_{l i}$ and $F_{2 i}$ are characterized by the membership functions $m_{l i}\left(e_{l}\right)$ and $m_{2 i}\left(e_{2}\right)$. Based on the standard fuzzy inference method (using a singleton fuzzifier, a product fuzzy inference and a weighted average defuzzifier), the final output $\eta_{f}(t)$ of the above fuzzy model can be represented as follows:

$$
\eta_{f}=\xi^{T} h(e)=\sum_{i=1}^{r} \xi_{i} h_{i}(e)
$$

where $\xi=\left[\xi_{1}, \cdots, \xi_{r}\right]^{T}$ is the adjustable parameter vector, and $h=\left[h_{1}, \cdots, h_{r}\right]^{T}$ is the fuzzy basis function vector given by:

$$
h_{i}(e)=\frac{\prod_{j=1}^{2} m_{j k}\left(e_{j}\right)}{\sum_{k=1}^{r} \prod_{j=1}^{2} m_{j k}\left(e_{j}\right)}, i=1,2, \cdots, r
$$




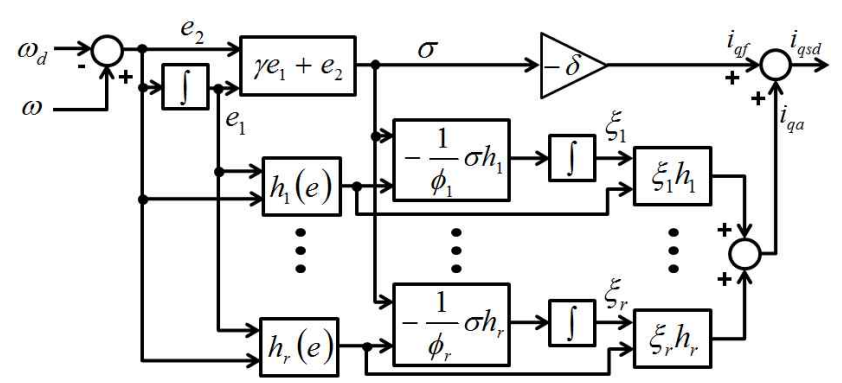

Fig. 2. Block diagram of the proposed fuzzy adaptive control algorithm.

It should be noted that $h_{i}$ can be regarded as the normalized weight of each IF-THEN rule and that they satisfy $h_{i} \geq 0$ and $\sum_{i=1}^{r} h_{i}=1$.

Let the optimal parameter vector be defined as $\xi_{*}$. Then the minimum approximation error is expressed as:

$$
\varepsilon=\eta-\eta_{f}=\eta-\xi_{*}^{T} h(e)=\sum_{i=1}^{r} \xi_{i^{*}} h_{i}(e)
$$

It should be noted that standard results such as [19] imply that a fuzzy system can uniformly approximate nonlinear functions to arbitrary accuracy. Thus if the searching space for $\eta_{f}(t)$ is sufficiently big, it can be assumed that $\epsilon=0$.

The $q$-axis current reference command $i_{q s d}$ can be decomposed as the feedback term $i_{q f}$ and the fuzzy adaptive compensating term $i_{q a}$ :

$$
i_{q s d}=i_{q f}+i_{q a}
$$

where:

$$
\begin{gathered}
i_{q f}=-\delta \gamma e_{1}-\delta e_{2}=-\delta \sigma \\
i_{q a}=\sum_{i=1}^{r} \xi_{i} h_{i}(e) \\
\xi_{i}=-\frac{1}{\phi_{i}} \int_{0}^{t} \delta h_{i} d \tau
\end{gathered}
$$

and $\delta>0, \gamma>0$, and $\phi_{i}>0$. Fig. 2 shows a block diagram of the proposed fuzzy adaptive control algorithm.

Theorem 2: Assume that the searching space for $\eta_{f}(t)$ is sufficiently big and that $\epsilon=0$. Let $i_{q s}=i_{q s d}$ be given by (15) with (16), (17), and (18). Then, $e$ converges to zero, and $\xi=$ $\left[\xi_{1}, \cdots, \xi_{r}\right]^{T}$ are bounded, respectively.

Proof: Define the Lyapunov functional as:

$$
V=\frac{1}{2}\left[\kappa e_{1}^{2}+\sigma^{2}+\sum_{i=1}^{r} \varsigma_{i} \widetilde{\xi}_{i}^{2}\right]
$$

where $\zeta_{i}=\phi_{i} k_{l}, \xi_{i}=\xi_{i^{*}}-\xi_{i}$, and $\kappa$ is a sufficiently small positive constant satisfying the inequality (8). Its time derivative along the error dynamics (4) is given by:

$$
\dot{V}=\kappa e_{1} \dot{e}_{1}+\sigma \dot{\sigma}-\sum_{i=1}^{r} \varsigma_{i} \widetilde{\xi}_{i} \dot{\xi}_{i}
$$

The equations (4), (14), $\epsilon=0$, and (15) imply that:

$$
\begin{aligned}
\dot{e}_{2} & =-\gamma e_{2}+k_{1}\left[-\delta \sigma+\sum_{i=1}^{r} \xi_{i} h_{i}-\varepsilon-\eta(t)\right] \\
& =-\gamma e_{2}+k_{1}\left[-\delta \sigma+\sum_{i=1}^{r} \xi_{i} h_{i}-\varepsilon-\sum_{i=1}^{r} \xi_{i} h_{i}\right] \\
& =-\gamma e_{2}-k_{1} \delta \sigma+k_{1} \sum_{i=1}^{r} \widetilde{\xi}_{i} h_{i}
\end{aligned}
$$

The time derivative of $e_{2}$ leads to:

$$
\dot{\sigma}=-\gamma \dot{e}_{1}+\dot{e}_{2}=-k_{1} \delta \sigma+k_{1} \sum_{i=1}^{r} \widetilde{\xi}_{i} h_{i}
$$

The equation (18) means that:

$$
\dot{\xi}_{i}=-\frac{1}{\phi_{i}} \sigma h_{i}
$$

Therefore, (19) can be reduced to:

$$
\dot{V} \leq \kappa e_{1}\left(\sigma-\gamma e_{1}\right)-k_{1} \delta \sigma^{2}=-e_{r}^{T} Q e_{r}
$$

where $Q$ is already defined in (12) and it is positive definite. This implies that:

$$
\lambda_{\min }(Q) \int_{0}^{\infty} e_{r}^{T} e_{r} d t \leq V(0)-V(\infty) \leq V(0)
$$

where $V(t) \geq 0$ is used. Since the smallest eigenvalue of $Q$, $\lambda_{\min }(Q)$, is positive, $\int_{0}^{\infty} e_{r}^{T} e_{r} d t \leq \infty$ can be obtained. This leads to $e_{r} \in L_{2} \cap L_{\infty}$ (i.e. $e_{1} \in L_{2} \cap L_{\infty}, e_{2} \in L_{2} \cap L_{\infty}, \sigma \in L_{2}$ $\cap L_{\infty}$.), and $\xi_{i} \in L_{\infty}$. From $\sigma=\gamma e_{1}+e_{2}$, the following transfer function relationship between $e_{1}$ and $\sigma$ can be obtained.

$$
H_{e_{1} \sigma}(s)=\frac{1}{s+\gamma}
$$

where $s$ is the Laplace variable. Because $H_{e_{1} \sigma}(s)$ is strictly positive real and $\sigma \in L_{2}$, Lemma 1 can be used to state that $e_{1}(t)$ converges to zero. Lemma 2 indicates that $e_{2}(t)$ converges to zero if $\dot{e}_{2}=\ddot{e}_{1}$ is bounded. Since $e_{2} \in L_{\infty}, \sigma$ $\in L_{\infty}, \xi_{i} \in L_{\infty}$, and $0 \leq h_{i} \leq 1$, by using (21) the following inequality can be known: 
TABLE I

PARAMETERS OF A PROTOTYPE SPMSM

\begin{tabular}{|c|c|}
\hline Number of poles $(p)$ & 12 \\
\hline Stator resistance $\left(R_{s}\right)$ & $0.99[\Omega]$ \\
\hline Stator inductance $\left(L_{s}\right)$ & $5.82[\mathrm{mH}]$ \\
\hline Magnetic flux $\left(\lambda_{m}\right)$ & $7.92 \times 10^{-2}[\mathrm{~V} \cdot \mathrm{sec} / \mathrm{rad}]$ \\
\hline Equivalent inertia $(J)$ & $1.21 \times 10^{-3}\left[\mathrm{~kg} \cdot \mathrm{m}^{2}\right]$ \\
\hline Viscous friction coefficient $(B)$ & $0.3 \times 10^{-3}[\mathrm{~N} \cdot \mathrm{m} \cdot \mathrm{sec} / \mathrm{rad}]$ \\
\hline
\end{tabular}

$$
\left|\dot{e}_{2}\right| \leq \gamma\left|e_{2}\right|+k_{1} \delta|\sigma|+k_{1} \sum_{i=1}^{r}\left|\widetilde{\xi}_{i}\right| \cdot\left|h_{i}\right|
$$

i.e., $\dot{e}_{2}$ is bounded, and thus it can be concluded that $e_{2}$ also converges to zero.

\section{PERformance Evaluation}

To present simulation and experimental results that can support the proposed control scheme, the parameters of a prototype SPMSM drive system are listed in Table I. Thus, (2) can be rewritten as the following dynamic equation:

$$
\dot{\omega}=3539.6 i_{q s}-0.2484 \omega-4968.8 T_{L}
$$

The following membership functions with $r=9$ are chosen to build the fuzzy model $\eta_{f}(t)$ given in (13):

$$
h_{i}=m_{1 i} / \sum_{j=1}^{r} m_{1 j}, m_{1 i}=e^{-\mu_{i}\left(\omega-\omega_{d}-W_{i}\right)^{2}}
$$

where $W_{1}=-W_{0}, W_{2}=3 W_{1} / 4, W_{3}=W_{1} / 2, W_{4}=W_{1} / 4, W_{5}=0$, $W_{9}=W_{0}, W_{8}=3 W_{9} / 4, W_{7}=W_{9} / 2, W_{6}=W_{9} / 4, \mu_{i}=1 / W_{0}^{2}$, and $W_{0}=50$.

With $\delta=0.2, \phi_{i}=0.1$, and $\gamma=1$, the $q$-axis current reference command $i_{\text {qsd }}$ can be expressed as the following control law:

$$
i_{q s d}=-0.2 \sigma+\sum_{i=1}^{9} \xi_{i} h_{i}
$$

where $\sigma$ is represented by:

$$
\sigma=\int_{0}^{t}\left(\omega-\omega_{d}\right) d \tau+\left(\omega-\omega_{d}\right)
$$

Also, $\xi_{i}$ is continuously updated by the following adaptation law:

$$
\xi_{i}(t)=-10 \int_{0}^{t} \sigma h_{i}(e) d \tau
$$

Fig. 3 shows an overall block diagram of the proposed control system. As illustrated in Fig. 3, the rotor position $(\theta)$ and the two phase currents $\left(i_{a}, i_{b}\right)$ are measured to carry out the closed-loop control. In addition, the overall control system is composed of two control loops: a proposed fuzzy adaptive speed controller in an outer loop and a conventional PI current controller in an inner loop. It is noted that the PI gains $\left(K_{P c}, K_{I c}\right)$ of the PI current controller are determined by the following gain tuning rule [21], [22]:

$$
K_{P c}=L_{s} \omega_{c}=1.82, \quad K_{I c}=R_{s} \omega_{c}=311.02
$$

where the bandwidth $\omega_{c}=2 \pi \cdot 50 \mathrm{rad} / \mathrm{s}$. In this paper, a Texas Instruments TMS320F28335 DSP is used to implement the proposed control algorithm as software. In both the simulation and the experiment, the PWM frequency is selected as $5[\mathrm{kHz}]$, and a space vector pulse-width modulation (SVPWM) method is employed to adjust the motor speed and torque according to the control input ( $V_{q s}$ and $\left.V_{d s}\right)$.

Figs. 4 and 6 show the simulation results of the proposed fuzzy adaptive speed controller using Matlab/Simulink under three conditions: speed transient response under nominal parameters, speed transient response and torque transient response under $200 \%$ variations of the stator resistance $\left(R_{s}\right)$ and the stator inductance $\left(L_{s}\right)$, respectively. In Figs. 4 to 5 , the desired motor speed $\left(\omega_{d}\right)$ is changed from $125.66[\mathrm{rad} / \mathrm{sec}]$ to $251.32[\mathrm{rad} / \mathrm{sec}]$ and then from $251.32[\mathrm{rad} / \mathrm{sec}]$ to 125.66 $[\mathrm{rad} / \mathrm{sec}]$. However, the load torque $\left(T_{L}\right)$ remains at $1[\mathrm{~N} \cdot \mathrm{m}]$. Fig. 4 shows the simulation results $\left(\omega_{d}, \omega, i_{q s d}, i_{q s}, i_{d s}, V_{a n}, i_{a}\right)$ of the speed transient response under nominal condition. On the other hand, Fig. 5 shows the simulation results of the speed transient response under $200 \%$ variations of the stator resistance $\left(R_{s}\right)$ and the stator inductance $\left(L_{s}\right)$. Fig. 6 shows the simulation results of the torque transient response under $200 \%$ variations of the stator resistance $\left(R_{s}\right)$ and the stator inductance $\left(L_{s}\right)$ when the load torque $\left(T_{L}\right)$ abruptly increases from $1[N \cdot m]$ to $2[N \cdot m]$ and then vice versa. However, the desired motor speed $\left(\omega_{d}\right)$ remains at $251.32[\mathrm{rad} / \mathrm{sec}]$. In Figs. 4 to 6 , it is clearly shown that the proposed fuzzy adaptive speed controller is very robust to uncertainties such as system parameter and load torque variations.

Figs. 7 and 8 show the experimental results of the proposed control method for the speed transient response and the torque transient response, respectively. Figs. 7 (a) and 8 (a) illustrate the desired speed $\left(\omega_{d}\right)$ and measured speed $(\omega)$, while Figs. 7 (b) and 8 (b) show the desired $q$-axis current $\left(i_{q s d}\right)$, the measured $q$-axis current $\left(i_{q s}\right)$, and the measured $d$-axis current $\left(i_{d s}\right)$. Figs. 7 (c) and 8 (c) show the phase $a$ voltage $\left(V_{a n}\right)$ and the phase $a$ current $\left(i_{a}\right)$. The simulation and experimental results demonstrate that the proposed fuzzy adaptive speed controller can guarantee outstanding speed control performance (i.e., fast transient behavior, accurate trajectory tracking capability, and robustness) without accurate information on the motor parameter and load torque values. 


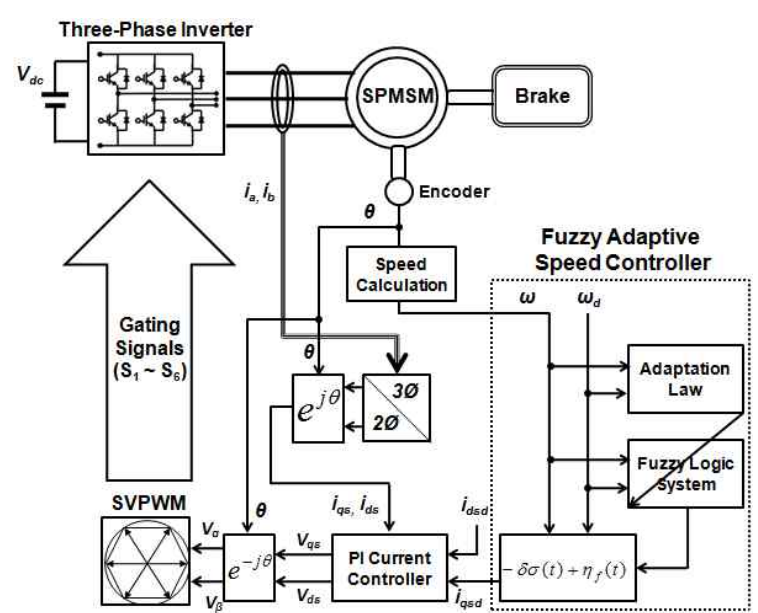

Fig. 3. Overall block diagram of the proposed control system.
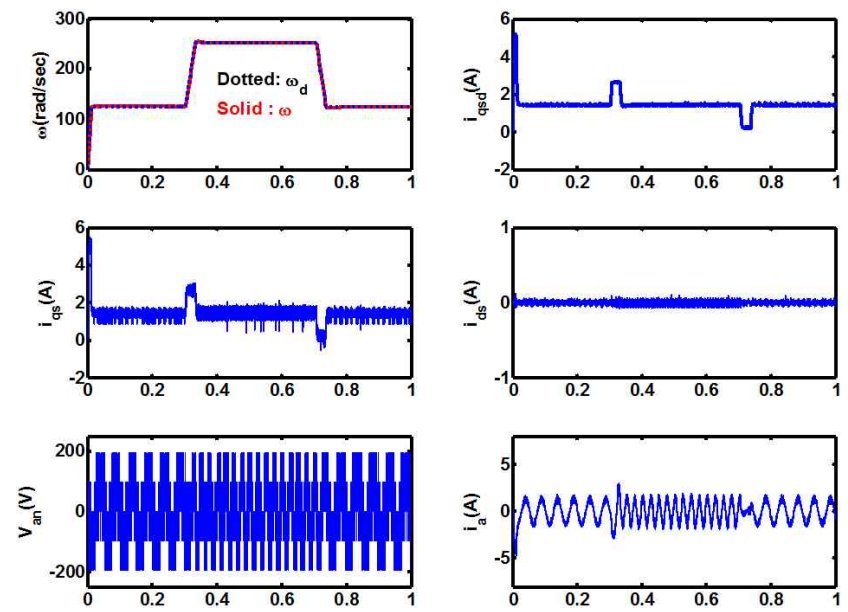

Fig. 4. Simulation results of speed transient response under nominal parameters when the desired speed $\left(\omega_{d}\right)$ suddenly changes.
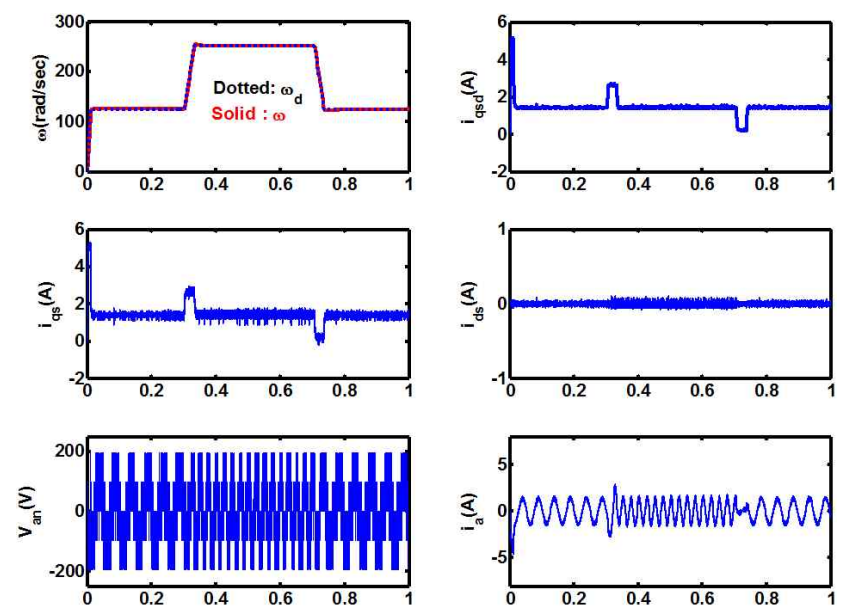

Fig. 5. Simulation results of speed transient response under $200 \%$ variations of some parameters $\left(R_{s}\right.$ and $\left.L_{s}\right)$ when the desired speed $\left(\omega_{d}\right)$ suddenly changes.
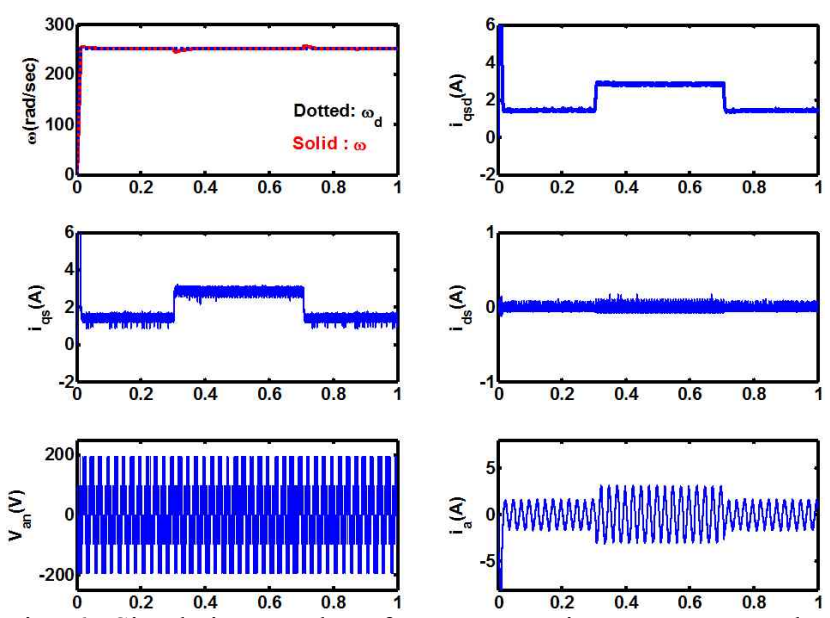

Fig. 6. Simulation results of torque transient response under $200 \%$ variations of some parameters $\left(R_{s}\right.$ and $\left.L_{s}\right)$ when the load torque $\left(T_{L}\right)$ suddenly changes.

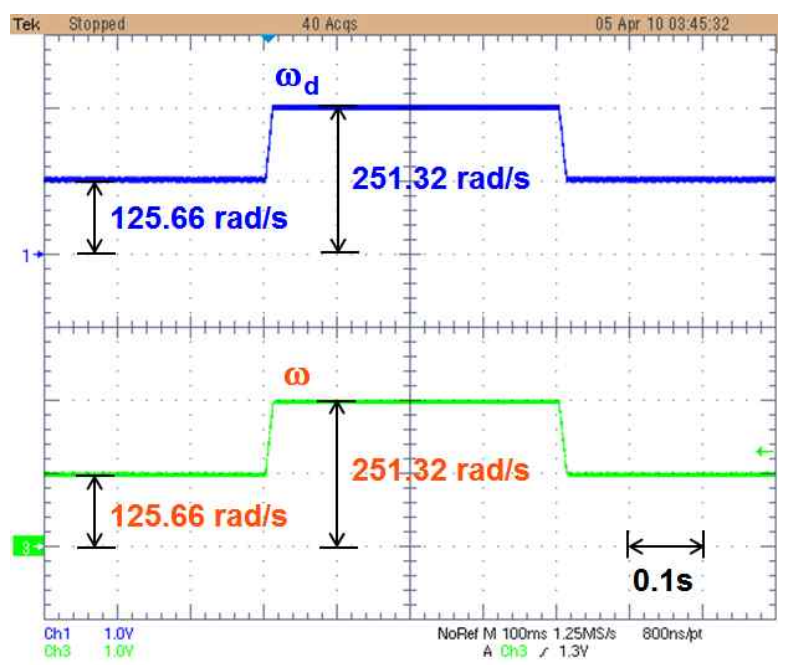

(a)

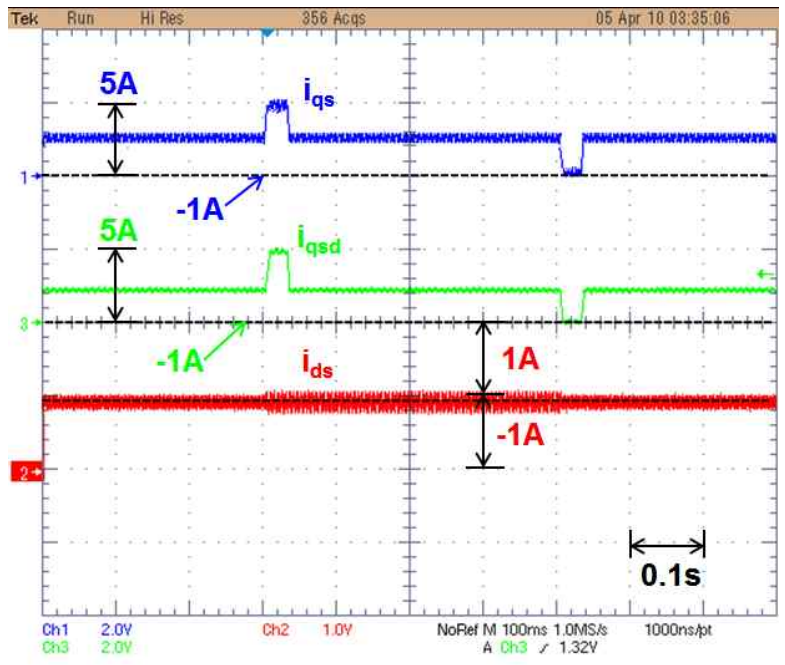

(b) 


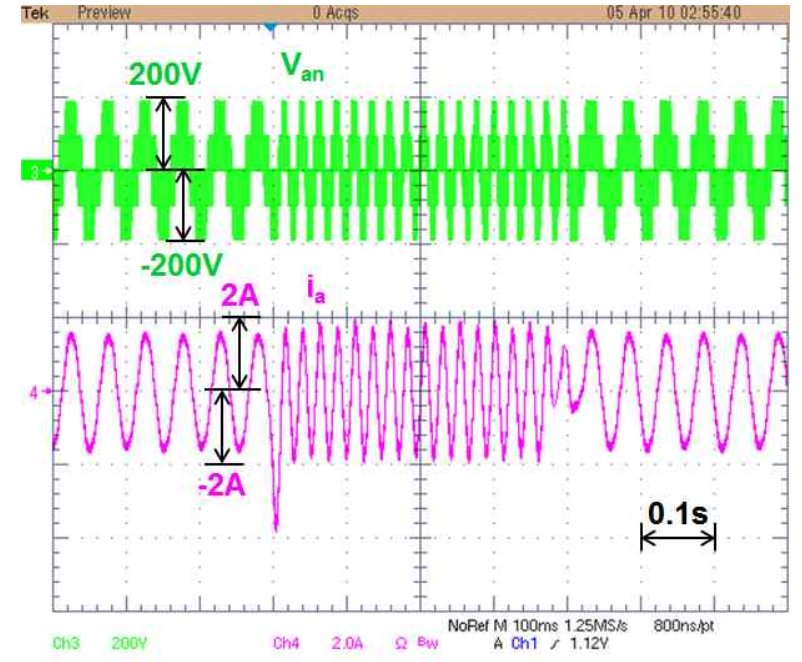

(c)

Fig. 7. Experimental results when the desired speed $\left(\omega_{d}\right)$ suddenly changes. (a) $\omega$ and $\omega_{d}$. (b) $i_{q s d}, i_{q s}$, and $i_{d s}$. (c) $V_{a n}$ and $i_{a}$.

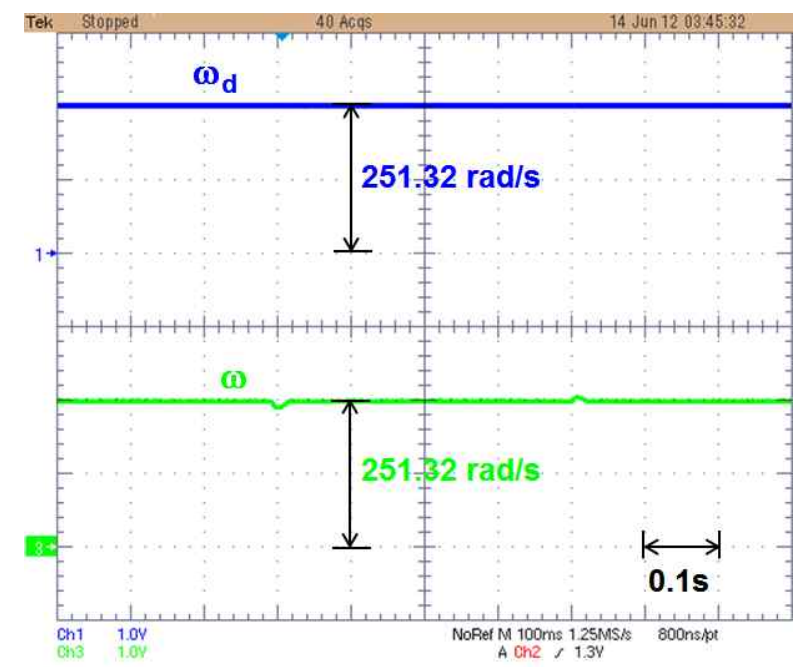

(a)

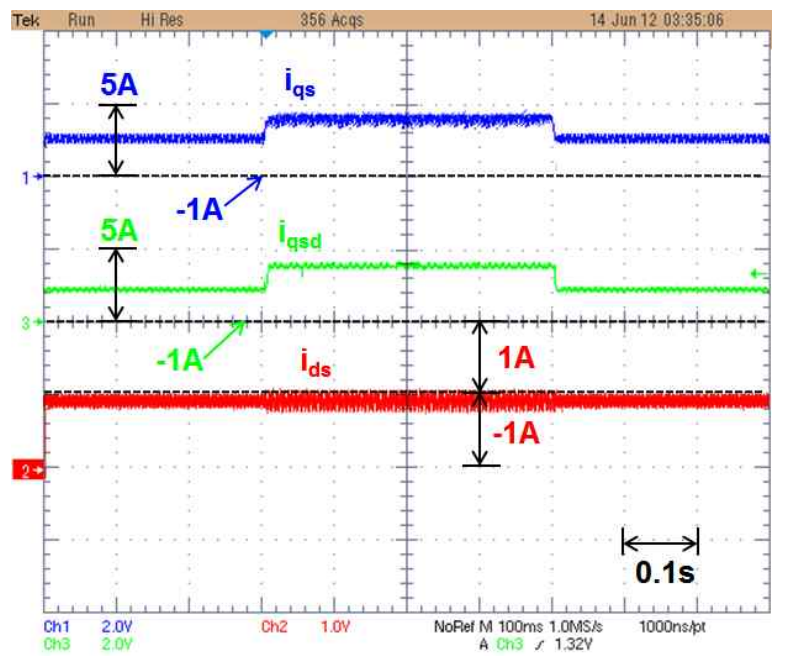

(b)

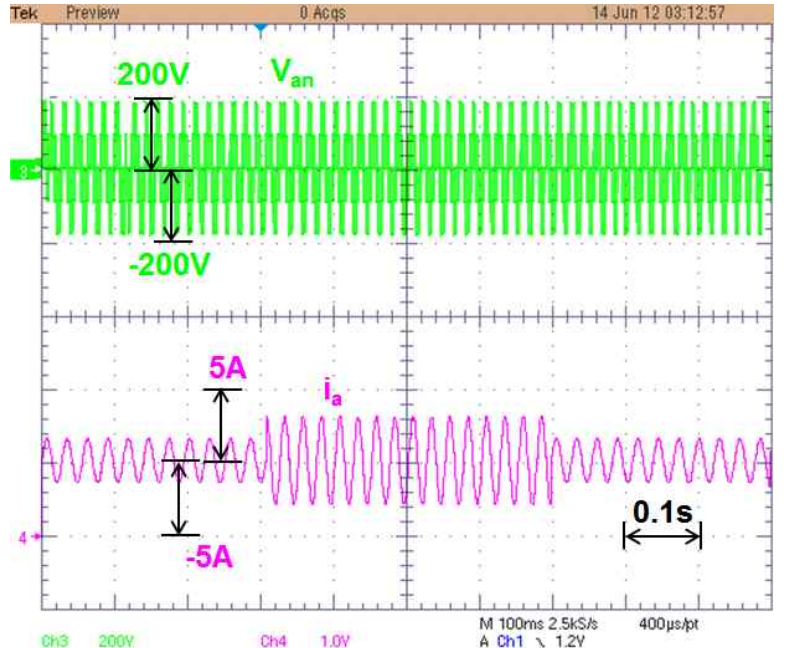

(c)

Fig. 8. Experimental results when the load torque $\left(T_{L}\right)$ suddenly changes. (a) $\omega$ and $\omega_{d}$. (b) $i_{q s d}, i_{q s}$, and $i_{d s}$. (c) $V_{a n}$ and $i_{a}$.

\section{CONCLUSIONS}

This paper proposed a fuzzy adaptive speed control strategy that can guarantee a fast transient behavior and a precise trajectory tracking capability for surfaced-mounted permanent magnet synchronous motors (SPMSMs). The proposed speed controller is very robust with respect to system uncertainties such as motor parameter and load torque variations. As a result, it does not require accurate parameter values. In addition, it was analytically proven that the proposed control system is asymptotically stable. In this paper, a conventional PI current controller was used together with the proposed fuzzy adaptive speed controller to examine the overall control performance. From the verification results, it can be seen that the proposed fuzzy adaptive control algorithm can be simply and easily implemented, and that it can assure excellent control performance such as fast dynamic response, accurate tracking capability, and robustness.

\section{ACKNOWLEDGMENT}

This work was supported by the Energy Efficiency \& Resources of the Korea Institute of Energy Technology Evaluation and Planning (KETEP) grant funded by the Ministry of Knowledge Economy, Republic of Korea (No. 2010T100200468).

\section{REFERENCES}

[1] H. S. Kang, C. K. Kim, and Y. S. Kim, "Position control for interior permanent magnet synchronous motors using an adaptive integral binary observer," Journal of Electrical Engineering \& Technology, Vol. 4, No. 2, pp. 240-248, Jun. 2009.

[2] Y. D. Son and G. H. Kang, "Drive system design for a 
permanent magnet motor with independent excitation winding for an electric bicycle," Journal of Electrical Engineering \& Technology, Vol. 5, No. 4, pp. 623-630, Nov. 2010.

[3] K. Hartani, Y. Miloud, and A. Miloudi, "Improved direct torque control of permanent magnet synchronous electrical vehicle motor with proportional-integral resistance estimator," Journal of Electrical Engineering \& Technology, Vol. 5, No. 3, pp. 451-461, Sep. 2010.

[4] K. Y. Cho, S. S. Hong, D. S. Oh, and M. J. Youn, "Speed control of permanent magnet synchronous motor using boundary layer state observer," Electronics Letters, Vol. 26, No. 25, pp. 2081-2083, 1990.

[5] K. B. Lee and F. Blaabjerg, "Robust and stable disturbance observer of servo system for low-speed operation," IEEE Trans. Ind. Appl., Vol. 43, No. 3, pp. 627-635, May/Jun. 2007.

[6] S. H. Choi, J. S. Ko, J. S. Park, and S. C. Hong, "Precise position control using a PMSM with a disturbance observer containing a system parameter compensator," IEE Proc.-Electr. Power Appl., Vol. 152, No. 6, pp. 1573-1577, 2005

[7] Y. Zhang, C. M. Akujuobi, W. H. Ali, C. L. Tolliver, and L. S. Shieh, "Load disturbance resistance speed controller design for PMSM," IEEE Trans. Ind. Electron., Vol. 53, No. 4, pp. 1198-1208, Jun. 2006.

[8] W. T. Su and C. M. Liaw, "Adaptive positioning control for a LPMSM drive based on adapted inverse model and robust disturbance observer," IEEE Trans. Power Electron., Vol. 21, No. 2, pp. 505-517, Mar. 2006.

[9] T. H. Liu, H. T. Pu, and C. K. Lin, "Implementation of an adaptive position control system of a permanent-magnet synchronous motor and its application," IET Elect. Power Appl., Vol. 4, No. 2, pp. 121-130, Feb. 2010.

[10] C. K. Lin, T. H. Liu, and S. H. Yang, "Nonlinear position controller design with input-output linearisation technique for an interior permanent magnet synchronous motor control system," IET Power Electron., Vol. 1, No. 1, pp. 14-26, Mar. 2008.

[11] J. Solsona, M. I. Valla, and C. Muravchik, "Nonlinear control of a permanent magnet synchronous motor with disturbance torque estimation," IEEE Trans. Energy Convers., Vol. 15, No. 2, pp. 163-168, Jun. 2000.

[12] Yi Yang, D. M. Vilathgamuwa, and M. A. Rahman, "Implementation of an artificial neural network based real-time adaptive controller for interior permanent motor drive," IEEE Trans. Ind. Appl., Vol. 39, No. 1, pp. 96-104, Jan./Feb. 2003.

[13] M. N. Uddin, M. A. Abido, and M. A. Rahman "Development and implementation of a hybrid intelligent controller for interior permanent motor dives," IEEE Trans. Ind. Appl., Vol. 40, No. 1, pp. 68-76, Jan/Feb. 2004.

[14] M. N. Uddin and M. A. Rahman, "High-speed control of IPMSM drives using improved fuzzy logic algorithms," IEEE Trans. Ind. Electron., Vol. 54, No. 1, pp. 190-199, Feb. 2007.

[15] Y. S. Kung, C. C. Huang, and M. H. Tsai, "FPGA realization of an adaptive fuzzy controller for PMLSM drive," IEEE Trans. Ind. Electron., Vol. 56, No. 8, pp. 2923-2932, Aug. 2009.

[16] M. Cheng, Q. Sun, and E. Zhou, "New self-tuning fuzzy PI control of a novel doubly salient permanent-magnet motor drive," IEEE Trans. Ind. Electron., Vol. 53, No. 3, pp. 814-821, Jun. 2006.

[17] S. Li and Z. Liu, "Adaptive speed control for permanent magnet synchronous motor system with variations of load inertia," IEEE Trans. Ind. Electron., Vol. 56, No. 8, pp. 3050-3059, Aug. 2009.

[18] G. Feng, "A survey on analysis and design of model based fuzzy control systems," IEEE Trans. Fuzzy Systems, Vol. 14, No. 5, pp. 676-697, Oct. 2006.

[19] J. L. Castro, "Fuzzy logic controllers are universal approximators," IEEE Trans. Syst., Man, Cybern., Vol. 25, No. 4, pp. 629-635, Apr. 1995.

[20] F. L. Lewis, C. T. Abdallah, and D. M. Dawson, Control of Robot Manipulators, Macmillan, 1993.

[21] H. Z. Jin and J. M. Lee, "An RMRAC current regulator for permanent magnet synchronous motor based on statistical model interpretation," IEEE Trans. Ind. Electron., Vol. 56, No. 1, pp. 169-177, Jan. 2009.

[22] R. H. Middleton and G. C. Goodwin, Digital Control and Estimation: A Unified Approach, Englewood Cliffs, NJ: Prentice - Hall, 1990.

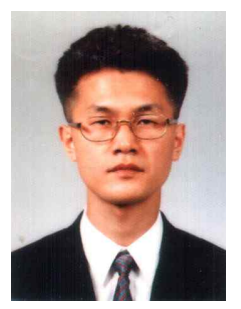

Jin-Woo Jung received his B.S. and M.S. in Electrical Engineering from Hanyang University, Seoul, Korea, in 1991 and 1997, respectively, and his Ph.D. in Electrical and Computer Engineering from The Ohio State University, Columbus, Ohio, USA, in 2005. From 1997 to 2000, he was with the Digital Appliance Research Laboratory, LG Electronics Co., Ltd., Seoul, Korea. From 2005 to 2008, he worked at the R\&D Center and with the PDP Development Team, Samsung SDI Co., Ltd., Korea, as a Senior Engineer. Since 2008, he has been an Associate Professor with the Division of Electronics and Electrical Engineering, Dongguk University, Seoul, Korea. His current research interests include electric machine drives, the control of distributed generation systems using renewable energy sources (wind turbines, fuel cells, solar cells, etc.), the design and control of power converters, and the driving circuits and driving methods of PDPs and LCDs.

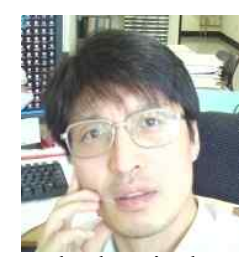

Han Ho Choi received his B.S. in Control and Instrumentation Engineering from Seoul National University (SNU), Seoul, Korea, in 1988, and his M.S. and Ph.D. in Electrical Engineering from KAIST, Daejeon, Korea, in 1990 and 1994, respectively. $\mathrm{He}$ is currently with the Division of Electronics and Electrical Engineering, Dongguk University, Seoul, Korea. His current research interests include control theory and its application to real world problems.

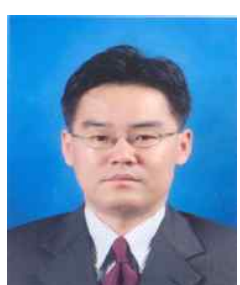

Dong-Myung Lee received his B.S. and M.S. in Electrical Engineering from Hanyang University, Seoul, Korea, in 1994 and 1996, respectively, and his Ph.D. in Electrical and Computer Engineering from the Georgia Institute of Technology, Atlanta, Georgia, USA, in 2004. From 1996 to 2000, he worked for LG Electronics Inc., Seoul, Korea. From 2004 to 2007, he was employed by the Samsung SDI R\&D Center, Yongin, Korea, as a Senior Engineer. From 2007 to 2008, he was with the Department of Electrical Engineering, Hanyang University, as a Research Professor. Since 2008, he has been an Associate Professor with the School of Electronic and Electrical Engineering, Hongik University, Seoul, Korea. His current research interests include variable speed drives, power quality compensation devices, and power conversion systems for renewable energy sources. 